THURSDAY, JUNE I8, I896.

\section{THE EVOLUTION OF COUNTING.}

The Number Concept: its Origin and Development. By Levi Leonard Conant, Ph.D. 8vo. Pp. 2r8. (New York and London: Macmillan and Co., 1896.)

PROF. CONANT has produced a book which sup1 plies a gap in scientific literature, and on it he has expended great diligence in collecting the materials, and circumspection in dealing with them. The problems of the origin and development of the number concept are important alike to the anthropologist and the psychologist, and all attempts to connect these two branches of science are most welcome; for the scope of the book, therefore, and for its execution, Dr. Conant is to be congratulated.

In a few instances, languages have been found to be absolutely destitute of pure numeral words; the Chiquitos of Bolivia, for example, expressed their idea for one by etama-"alone"-they had no real numerals. A few other South American languages are almost equally destitute of numeral words, but some indirect expression shows a conception of the difference between $\mathrm{I}$ and 2 , or, at least, between I and many.

There is a surprising paucity of numeral words among the native races of South America, Australia, New Guinea, and among the Pigmy peoples. Many of these have only two numerals. It is probably true that no Australian language contains a pure, simple numeral for 4; a few tribes have a numeral for 3. The same obtains for the Papuan as opposed to the Melanesian tribes of British New Guinea, whereas the numerals of the latter (S. H. Ray, Trans. Internat. Congr. Orientalists, London, 1892-93, p. 770) have decided affinities with those of the Melanesian archipelagoes. It is also characteristic of the Australians and the Papuans (as here restricted) to count by pairs; but this is not a Melanesian custom, though it is employed in Polynesia. The Mincopies (Andaman Islands) and the Veddas have numerals for only $I, 2$, beyond which they say "and one more, and one more," \&c.; for the Bushmen, 3 means simply many. The Pigmies of Central Africa, according to Stanley, have separate numerals up to 6 , but the words for I (ujju) and 6 (ijju) are so closely akin, that it suggests that 6 was to them a new I. These Pigmy people are considerably in advance of the others just referred to, so far as their system of numeration is concerned.

The author carefully points out that it is not a general law that those races which are lowest in the scale of civilisation have the feeblest number sense or the least possible power of grasping the abstract idea of number. If the life of any tribe is such as to induce trade and barter, a considerable quickness in reckoning will be developed among them. In giving $1,2,3,5$, 10, or any other small number as a system limit, it must not be overlooked that this limit mentioned is in all cases the limit of the spoken numerals at the savage's command. The actual ability to count is almost always, if not always, somewhat greater than their vocabularies would indicate. By means of their fingers, toes, or other parts

$$
\text { NO. I } 390 \text {, vOL. 54] }
$$

of their body, or by the aid of sticks and other objects, the savages with even the lowest number concept can indicate higher numbers than their spoken numbers. Most proceed with more or less readiness as far as their fingers will carry them, and this limit is frequently extended to 20 .

The primitive savage counts on his fingers until he has reached the end of one, or more probably of both, hands. Then if he wishes to proceed further some mark is made, a pebble is laid aside, a knot tied, \&c., to signify that all the counters at his disposal have been used. Then the count begins anew, the terms already used are again resorted to, and the name by which the first halting-place was designated is repeated with each new numeral; hence thirteen, fourteen, \&c. In Teutonic languages the smaller number is prefixed to the base, e.g., fiinf und zwanzig; but the direct method (twenty-five) is far more common, though both are found in all parts of the world.

The formation of numeral words by subtraction, though it seems decidedly odd to us, is of common occurrence. In Latin, 19 is undeviginti (I from 20); the Bellacoola, of British Columbia, say for 19 "one man less I," as in their numeral scale 20 is "one man," for them 15 is "one foot," and I6 "one man less 4." Many tribes seem to regard 9 as "almost Io," and to give it a name which conveys this thought.

The following Zuñi scale is interesting :-

I, "taken to start with."

2, "put down together with."

3 " "the equally dividing finger."

4 , "all the fingers but one done with."

5 , "the notched off."

6, "another brought to add to the done with."

7 , "two brought to and held up with the rest."

8, "three brought to and held up with the rest.

9, "all but all are held up with the rest."

Io, "all the fingers."

II, "all the fingers and another over above held."

20 , "two times all the fingers."

roo, "the fingers all the fingers.

IOOO, "the fingers all the fingers times all the fingers."

While the savage almost always counts on his fingers, it does not seem at all certain that these words would necessarily be of finger formation. The numerals for $I$ and 2 would be formed long before the need would be felt for terms to describe any higher number. Universal as finger counting has been, finger origin for numeral words has by no means been universal. In nearly all languages the origin of the words for $1,2,3$, and 4 are so entirely unknown that speculation respecting them is almost useless.

The first real difficulty which the savage experiences in counting, the difficulty which comes when he attempts to pass beyond 2 , and to count 3, 4, and 5 , is of course slight. Beyond 5, primitive man often proceeds with the greatest difficulty. Whenever the fingers and hands are used at all, it would seem natural to expect for 5 some general expression signifying hand, for Io both hands, and for 20 man. Such is the ordinary method of progression, but some people express Io by $m a n$, perhaps because they do not use the toes in counting; thus the Api word for 200 is "Io times the whole man taken 2 times." 
Without the establishment of some base, any system of numbers is impossible. A binary system is characteristic of Australia, but it occurs elsewhere ; instances of quaternary numeration are less rare than are those of ternary, and there is reason to believe that this method of counting has been practised more extensively than any other, except the binary and the three natural methodsthe quinary, the decimal, and the vigesimal. There is probably no recorded instance of a number system formed on $6,7,8$, or 9 as a base.

In its ordinary development the quinary system is almost sure to merge into either the decimal or the vigesimal system, and to form with one or the other, or both of these, a mixed system of counting. Whether or not the principal number base of any tribe is to be 20 , seems to depend entirely upon a single consideration-are the fingers alone used as an aid to counting, or are both fingers and toes used? If the former, the resulting scale must become decimal. The quinary is never the principal base in any extended system. The Celtic races showed a preference for counting by twenties, which is almost as decided as that manifested by the Teutonic races for counting by tens.

With such a vast field from which to collect materials for his study, it is inevitable that Prof. Conant should have overlooked some authors who might have furnished him with additional examples, and that he should have made a few slips. Among the omissions may be noted Dr. Von den Steinen's discussion on the numeration of the Bakaïri in his "Unter den Naturvölkern ZentralBrasiliens," Mr. Ray's studies in the languages of New Guinea, Mr. H. Clifford's account of the Negritos of the Malay Peninsula (J.Roy. As. Soc. Straits Br., I 892), Dr. S. Günther's study on numerical systems (Beitr. Anth. Urgesch. Bayerns, 1890, ix.). On p. 96 the Torres Islands in the New Hebrides are confused with Torres Straits, and the languages of Darnley Island (p. 24) and Warrior Island (p. I07) are Papuan (Torres Straits), and not Australiàn dialects. Anthropologists would have been thankful if the ethnological aspect of the question had been dwelt upon a little more fully ; for example, the ethnologist is not at a loss to account for the superior development of the number sense in the Nicobarese as compared with that of the neighbouring Andamanese. The book is admirably printed, and is packed with valuable information clearly and logically arranged.

A. C. Haddon.

\section{GEOMORPHOGENY.}

Leçons de Géographie physique. Par Albert de Lapparent. Pp. xvi. + 590. Illustrations. (Paris: Masson et Cie., 1896.)

IF Prof. de Lapparent had been writing in America, 1 he would have introduced the word Geomorphogeny in the title of his latest book ; but in Europe, he observes in the preface, there is some risk of frightening those whom he would wish to instruct if they are confronted by an unfamiliar term at the outset. The title "Lessons in Physical Geography," although quite without terror, is not fairly descriptive, for this fine volume is no ordinary treatise of physical geography in the usual No. I 390 , VOL. 54] vague sense. "Lessons on the Genesis of Geographical Forms" would, in the author's view, and in ours, be more descriptive; but the full scope of the work would, perhaps, hardly be suggested even by such a title.

Whatever he may call it, a book by Prof. de Lapparent is sure of a cordial reception by students and men of science in all parts of the world, for he combines the traditional grace and charm of French scientific writers with a temperateness of judgment and width of view which, rightly or wrongly, foreigners do not always associate with the writings of his countrymen. The avowed object of the work is to furnish a body of doctrines, logically linked together, which shall help to place geography on a truly rational basis. This basis is, in Prof. de Lapparent's opinion, a geological one, for he argues that the knowledge of no geographical form can be complete unless its antecedent conditions are known, and in geology alone can the clue to these be found. We might perhaps demand an even deeper foundation than geology, by taking into account the relations of form and position and the means of determining these mathematical conditions by astronomical observations; but geology may be freely accepted as the layer in the pyramid of geographical science which comes immediately below physical geography, and is most indissolubly connected with it.

The volume takes the form of twenty-five "lessons" or chapters; but it may be divided into two parts, approximately equal in bulk-the enunciation of the genera! principles of geomorphogeny, and the application of these to the configuration and structure of each of the continents. The great lines of terrestrial relief are first outlined, and the conditions of land-modelling are then discussed in fuller detail and with a more comprehensive grasp than in any other book of the kind with which we are acquainted. The various agencies at work on the land-surface are treated in turn, and their action illustrated by a great wealth of instances. The normal course of erosion in a region is first explained, and the various complications introduced by structural con ditions, classed as genetic and tectonic, are then introduced. Genetic conditions are those produced by the original formation of the portion of land under consideration, e.g. whether sedimentary, igneous, or glacial ; tectonic are those subsequently produced by movements of the crust. Considering the predominant part played in the modelling of the land by running water, it is natural that several lessons should be devoted to this agency, in the discussion of which a prominent place is given to the view of the cycle of erosion so vigorously set forth of recent years by Prof. W. M. Davis, of Harvard. One can hardly say of any part of this theory that it is new. Geologists have worked so long at the phenomena of erosion, that it is now difficult to fit each stage of the process with the name of the first observer or theoriser. But there is no doubt that, however universally the knowledge of the processes of the origin of scenery by denudation were known, the credit for expressing the nett result of them in terse and appropriate language is due to Prof. Davis, and his mode of statement is accepted by Prof. de Lapparent with full acknowledgment. The conception of the origin of surface features through a process of evolution, a continuous succession 